\title{
Erratum to: Temporal changes in wetland plant communities with decades of cumulative water pollution in two plateau lakes in China's Yunnan Province
}

\author{
WANG Si-hai1,2,3 iDhttps://orcid.org/oooo-ooo2-4143-4919; e-mail: wangsh6688@163.com \\ WU Chao' (D)https://orcid.org/oooo-ooo2-8724-1434; e-mail: 1073895932@qq.com \\ XIAO De-rong2 iDhttps://orcid.org/oooo-0oo3-2311-4716; e-mail: xiaoderong1@163.com

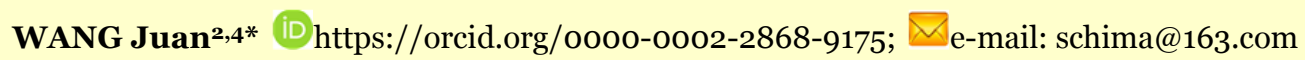 \\ CHENG Xi-ping5 iDhttps://orcid.org/oooo-0002-5461-6527; e-mail: xipingcheng2012@163.com \\ GUO Fang-bin5 iDhttps://orcid.org/oooo-0oo2-5540-5836; e-mail: guodelinlin@163.com \\ * Corresponding author \\ 1 Key Laboratory of the State Forestry Administration on Conservation of Rare, Endangered and Endemic Forest Plants, \\ Yunnan Academy of Forestry, Kunming 650201, China \\ 2 National Plateau Wetlands Research Center, Southwest Forestry University, Kunming 650224, China \\ 3 State Key laboratory of Phytochemistry and Plant Resources in West China, Kunming Institute of Botany, Chinese Academy \\ of Sciences, Kunming 650201, China \\ 4 Yunnan Provincial Key Laboratory of Cultivation and Exploitation of Forest Plants, Yunnan Academy of Forestry, Kunming \\ 650201, China \\ 5 Faculty of Ecotourism, Southwest Forestry University, Kunming 650224, China
}

Citation: Wang SH, Wu C, Xiao DR, et al. (2022). Erratum to: Temporal changes in wetland plant communities with decades of cumulative water pollution in two plateau lakes. Journal of Mountain Science 19(7). https://doi.org/10.1007/s11629-018-4843-3

(C) Science Press, Institute of Mountain Hazards and Environment, CAS and Springer-Verlag GmbH Germany, part of Springer Nature 2022

Erratum to: J. Mt. Sci. (2017) 14(9): 1677-1688

https://doi.org/10.1007/s11629-016-4037-9

The Electronic Supplementary Material of the article entitled "Temporal changes in wetland plant communities with decades of cumulative water pollution in two plateau lakes in China's Yunnan Province" at https://doi.org/10.1007/s11629-016-4037-9 are swapped with the Electronic Supplementary Material of the article entitled "Tracing environmental lead sources on the Ao mountain of China using lead isotopic composition and biomonitoring" at https://doi.org/10.1007/s11629-016-4327-2.

\section{Electronic supplementary material:} Supplementary materials (Appendixes 1, 2, 3) are available in the online version of this article at https://doi.org/10.1007/s11629-018-4843-3.

The online version of the original article can be found at https://doi.org/10.1007/s11629-016-4037-9 